\title{
Humanitarian Intervention, Health Behavior and Health Outcomes in Conflict Affected North East Nigeria: A Cross Sectional Survey Study
}

Esther Ariyo ( $\nabla$ esther.ariyo@uantwerpen.be )

University of Antwerp Belgium https://orcid.org/0000-0001-9827-7005

\section{Edwin Wouters}

Universiteit Antwerpen

Dimitri Mortelmans

Universiteit Antwerpen

\section{Research}

Keywords: WASH, Nigeria, diarrhea, health behavior, conflict-affected, bathing, diarrhea, sickness, children, cross-sectional, humanitarian intervention, internally displaced

Posted Date: April 10th, 2020

DOI: https://doi.org/10.21203/rs.3.rs-21995/v1

License: (c) (i) This work is licensed under a Creative Commons Attribution 4.0 International License. Read Full License 


\section{Abstract}

Background: The study explores the health behavior and outcomes (bathing, diarrhea, and sickness) of children who benefitted from a WASH package intervention, children who benefitted from a non-WASH sectoral form of intervention and children with no form of humanitarian intervention in conflict-affected communities in Northeastern part of Nigeria.

Methods : We analysed data collected through a pretested questionnaire administered to a randomly selected sample of 385 children aged 7 to 18 years living within six conflict-affected communities using descriptive and regression analysis.

Results : $39.4 \%$ of children from households that benefitted from WASH intervention had good environmental hygiene as compared to children from households with no humanitarian intervention $(10.5 \%)$ and children who had benefited from the non-WASH related intervention (10.3\%). We found that environmental hygiene is positively related to all outcomes measured. Study results also indicate that food security and socioeconomic status are associated with the frequency of sickness of internally displaced children. However, we found no significant difference in health outcomes across the intervention groups.

Conclusion : Findings suggest the need for children-oriented WASH programming with an emphasis on environmental hygiene for households and communities. We also confirm existing evidence on the importance of integrated multi-sectoral humanitarian interventions in improving the health of crisisaffected children.

\section{Background}

In the North East Region of Nigeria, the insurgent activities of Boko Haram have forced 2 million people to flee and become internally displaced, of which about half are children(1). Internally displaced persons (IDPs) are 'persons or groups of people who have been forced or obliged to flee or leave their homes or places of habitual residence, in particular as a result of, or in order to avoid the effects of armed conflicts, situations of generalised violence, violations of human rights or natural or human-made disasters, and who have not crossed an internationally recognised state border'(2).

Internal displacement has a significant impact on the health and well-being of the affected populations (3-7), especially children. Diseases such as respiratory infections, diarrhoea, scabies, malaria and measles are common among displaced children (8-10). For instance, a study of Uganda IDP camps revealed that the most prevalent symptoms among children in the IDP camps were fever, cough and diarrhoea (3). These are mainly caused by inadequate sanitation, poor hygiene and inadequate water supplies $(4,8,11-13)$. As a result, adequate sanitation, water supplies and good hygiene are essential determinants for the survival of displaced populations $(6,13)$. 
The Hygiene Improvement Framework (HIF) postulates that a comprehensive approach that entails: (i) improving access to water and sanitation (ii) promotion of hygiene and (iii) strengthening an enabling environment are all essential to promoting hygienic household behaviors. These subsequently reduces the transmission of diseases and promotes better health outcomes. Furthermore, researchers have argued that water supply, sanitation and hygiene promotion interventions should be implemented as a package and should not be disaggregated $(6,14,15)$.

In line with the Hygiene Improvement Framework (HIF), humanitarian programs carried out by agencies use Water, Sanitation, and Hygiene interventions (WASH), these kinds of interventions are used to mitigate disease risk and improve health in emergency settings (12).WASH interventions usually consist of a combination of improvements to water supply, sanitation and hygiene promotion in order to reduce the transmission of infectious diseases through the promotion of good hygiene practices, the provision of safe drinking water and the reduction of environmental health risks $(6,11,12)$. WASH package interventions are usually carried out concurrently and usually consist of water point rehabilitation, hygiene kit distributions and hygiene promotion (16).

In non-emergency settings, WASH package interventions - as well as the general Hygiene Improvement Framework (HIF) on which they are based - have been found to improve hygiene behaviours and subsequently improve health. For instance, adequate water supply was reported to improve household hygiene behaviour ( handwashing, bathing, food washing, and household cleaning) in a study conducted in Bangladesh (17). Likewise, in the Democratic Republic of Congo, there was an increase in handwashing practices, a hygienic display of market goods and a 50\% reduction in diarrhoea prevalence among children of market sellers after water-point units were used to teach the community members about hygiene as the hygiene promotion component of an intervention. The intervention had the construction of water and sanitation facilities as the water and sanitation component. Also, the maintenance of the facilities was implemented by private business as the enabling environment component (18).

Examples of activities in the HIF components are: (i) improved access to water and sanitation, which could be the provision of soaps, safe water containers, and effective water treatments. (ii) Promotion of hygiene, which entails communication, social mobilisation and social marketing and (iii) strengthening of enabling environment which could be community involvement, institutional strengthening, financing and cost recovery activities, and policy improvement.

However, evidence on the effect of a comprehensive WASH package intervention on hygiene behaviour, and the subsequent effect on health outcomes in an emergency setting are scanty and inconclusive. For instance, a study in hurricane-affected communities in the Dominican Republic reported a $16 \%$ increase in handwashing practices before eating for children after the implementation of a comprehensive HIF WASH intervention(19). Likewise, a study in a Malawi refugee camp reported that the availability of regular soap within the household reduces the occurrence of diarrhea in the refugee population (20). Whereas a study in a South Sudan refugee camp, after a disease outbreak, reported poor levels of proper 
handwashing behaviour despite hygiene education and availability of soap and water within the camps(21). Similarly, studies from Kenya, Thailand and Ethiopian refugee camps reported low handwashing behaviour despite hygiene education within the camps(22). With the large number of people who are displaced and are at risk of communicable diseases, more substantial evidence is needed $(6,8,11,12,23-28)$. Additionally, it has been suggested that evidence on the health outcomes of WASH interventions should distinguish between the type of crisis (either natural disaster or conflict), the type of community (rural or urban), the type of displacement (internally or externally) and children $(11,29)$.

The objectives of this study are to fill these knowledge gaps by looking at the relationship between (1) a WASH package intervention, (2) socio-demographic characteristics, (3) personal hygiene behaviour (i.e. bathing) and (4) health outcomes (becoming sick and having diarrhea), for children who are internally displaced due to conflict in rural communities. Bathing in this study is the washing of the body with soap for body cleanliness to provide general personal hygiene, comfort and relief (30). We hypothesise that (1) the WASH intervention would improve bathing frequency among children and that (2) Bathing frequency will negatively affect the frequency of sickness and occurrence of diarrhea among the children.

\section{Methods}

\section{Methods}

We conducted a cross-sectional survey within locations where TEAFUND and CRUDAN (Nongovernmental organisations) carried out a humanitarian intervention in conflict-affected locations of Northeast Nigeria. The study sites are rural and/or conflict-affected communities in early stages of recovery, with multi-sectoral interventions running concurrently within the communities. The humanitarian interventions executed in the communities include WASH packages, psycho-social support activities, education support, food and livelihood support, and health facility support.

The WASH intervention was implemented as a package (beneficiaries of the WASH intervention received the WASH package) in accordance with the HIF proposed components for health programs. The WASH intervention includes Water, Sanitation, Hygiene promotion and community involvement. The enabling environment component consisted of stimulating community involvement. This was carried out by setting up committees within the community for the coordination, maintenance and management of the water and sanitation facilities and activities. See Table 1 for details of activities within each sector.

\section{Table1:}

Intervention activities. 
WASH package Intervention activities

- Construction of water outlets

- Rehabilitation of water outlets

- Construction and rehabilitation of toilets

- Distribution of water containers and storage facilities

- Distribution of hygiene and sanitation products

- Hygiene education/ promotion through community sanitation and water point messages

- Community involvement

\section{Non-WASH (other sectoral) intervention}

- Food and livelihood support activities (vocational training, food vouchers/ basket, unconditional cash transfer)

- Educational support for children (distribution of learning materials and funds)

- Psycho-social and protection activities (parenting training, and counselling)

- Health intervention through health personnel and facilities

We purposively selected two study sites based on (1) security reasons and (2) the fact that XXX and YYYY, two non-governmental organisations, carried out food and livelihood support (FSL), and water sanitation and hygiene (WASH). Within these selected study sites, a random sample of 395 children was selected with the help of community leaders and school administrators.

Ethical clearance was obtained from the University of Antwerp Ethics Committee for Social Science and Humanities, and from the National Emergency Management Agency (NEMA), Nigeria. Written informed consent was obtained from all study participants (as well as their caretakers) after information about the study was explained to the participants by adult caretakers. We additionally obtained oral consent from each child before their participation in the study. Information sheets were given to all participants (adult caretakers and children) in the local language and in English. No names were obtained or recorded. The surveys were administered by research assistants that had previous experience conducting research with children. Surveys were administered to children (within a reasonable distance) in the presence of adult caretakers. In addition, research assistants were trained on ethical issues and the administration of questionnaires to children before the pretest of the instruments. Participants were informed at the time of the data collection that their answers were anonymous, confidential, and voluntary. No incentives were offered to study participants. The response rate was very high (100\%) - this could be caused by the fact that the community members might have thought that the survey conducted would result in some kind of humanitarian aid, as our study procedure potentially resembled the enrollment procedure of humanitarian organisations which were active in the community. The primary researcher and field assistants handled the misconception by explaining clearly to the study participants that the study was not associated with or would not result in any future humanitarian aid. Cases of child neglect identified through this research were referred to the appropriate agencies using the already established NGO referral network. 
We used a questionnaire that was adapted from a previous study with refugee children(31), backtranslated it into Hausa pidgin language and pretested it in a displacement settlement different from the study (Adamawa town) location before use. Data was collected using the Kobo collect application on mobile phones. After the pretest, corrections were made to the survey instrument, and potential challenges on the field and associated solutions were also explored.

The sampled population were grouped into three groups based on the intervention activity/activities received. The three relevant groups were "No intervention", "At least WASH" and "Non-WASH" groups. The "No intervention" group consisted of children who had not received any intervention activity. The "At least WASH" were children who benefited from the WASH package intervention and potentially also another Non-WASH related activity. We did not find sufficient number of people that only received WASH intervention (only 5 people received WASH intervention alone). The "Non-WASH" group are children who benefited from any non-related WASH activity/activities only.

Outcomes measured were (i) health behaviour measured by frequency of bathing within a week, (ii) health outcomes assessed by (a) frequency of sickness in the last three months on a scale of $0-6$, and (b) being sick of diarrhoea within the last month and (yes or no).

The questionnaire includes questions on age, gender, household assets (measured by household property ownership), household food security (measured by frequency of sleeping hungry at night and frequency of inadequate food at home), and an environmental hygiene scale with Cronbach alpha of 0.69 . These were used as control variables in our model.

The environmental hygiene scale was assessed by the presence of household designated toilets, overcrowding within household spaces, damaged windows and/or doors, adequate hygiene items, lighting within the living space and the presence of dirt within the environment of the house.

\section{Analysis}

First, we use IBM SPSS Statistics 22 (Armonk, NY) to assess the descriptive statistics and differences within the groups. Second, structural equation modelling was used to estimate the strength of the hypothesised relationships between variables and determine the goodness-of-fit of the hypothesised model using Mplus V8.3 software (32). This technique allows the assessment of direct and indirect effects among the variables in the model. Two models were tested: one with diarrhea (model A) as the final outcome and one with sickness (model B) as the final outcome. As shown in figure 1, the control variables and intervention groups were assumed to have a direct effect on the dependent variables (bathing, diarrhea and frequency of sickness). The WASH intervention is also assumed to have an indirect effect on diarrhea (model A) or frequency of sickness (model B) through bathing. The MLR (maximum likelihood with robust standard errors) estimator was used to account for non-normality in the outcome distribution. We tested for fitness model fit using the comparative fit index (CFI) (33), the 
Tucker-Lewis index (TLI) (34), and the root mean square error of approximation (RMSEA) (35). The CFI and TLI assess the model fit by contrasting the hypothesised model to the worst possible fitting model. The closer the value of CFI and TLI approaches 1, the better the fitness of the proposed model. A good $\mathrm{CFI}$ and TLI value is usually greater than .90 . The RMSEA assesses absolute fit, and the value of model misspecification shows close fitness as the value approaches 0 . A good fit is typically set to be smaller than .05 . Due to the diversity in the nature of the outcome variables measured in this study (sickness is a continuous variable, diarrhoea a binary variable and bathing a continuous variable), the statistical program did not allow for the testing of the goodness- of-fit for the diarrhoea model so it could not be measured.

As having diarrhoea is a binary outcome probit regression was used to explain this outcome, while all other coefficients in the two models are standardised linear regression coefficients. The diagram of the model tested is shown in figure 1.

Figure 1: Diagram of models tested

\section{Results}

The population had a mean age of $13.53(S D=5.73)$. The No Intervention group is the largest group with $(n=294)$, the Non-Wash $(n=68)$ while the "at least WASH" group had the smallest sample size $(n=33)$. With the aid of bivariate analyses, we examined the socio-demographic differences of the intervention groups to include household assets and household food security. We found that children in the "at least WASH" intervention group had a lower significant household asset score than the other groups. The demographic characteristics, stratified by intervention group, are shown in Table 2.

\section{Table 2}

\section{Demographic characteristics by groups}




\begin{tabular}{|c|c|c|c|}
\hline & $\begin{array}{l}\text { No } \\
\text { intervention }\end{array}$ & $\begin{array}{l}\text { At least } \\
\text { WASH }\end{array}$ & $\begin{array}{l}\text { Non-WASH } \\
\text { intervention }\end{array}$ \\
\hline Age mean (S.D) & $\begin{array}{l}13.70 \\
(5.48)\end{array}$ & $\begin{array}{l}13.58 \\
(7.51)\end{array}$ & $12.80(5.84)$ \\
\hline Male N (\%) & $\begin{array}{l}130 \\
(44.4 \%)\end{array}$ & 11(33.3\%) & $32(47.1 \%)$ \\
\hline Female N (\%) & $163(55.6 \%)$ & $22(66.7 \%)$ & $36(52.9 \%)$ \\
\hline \multicolumn{4}{|l|}{$X^{2} 1.798, d f 2, p=.407$} \\
\hline $\begin{array}{l}\text { Index of household asset } \\
\text { (on a scale of } 0-4 \text {, with } 4 \text { as the highest asset } \\
\text { score) }\end{array}$ & $\begin{array}{l}\text { Score } 0 \\
15.6 \% \\
119.4 \% \\
229.3 \% \\
319.7 \% \\
416.0 \%\end{array}$ & $\begin{array}{l}42.4 \% \\
24.2 \% \\
21.2 \% \\
12.1 \% \\
-\end{array}$ & $\begin{array}{l}14.7 \% \\
16.2 \% \\
20.6 \% \\
23.5 \% \\
25.0 \%\end{array}$ \\
\hline \multicolumn{4}{|l|}{$X^{2} 25.248, d f 8, p=.001^{*}$} \\
\hline $\begin{array}{l}\text { Household food security index } \\
\text { (on a scale of } 0-2 \text {, with } 2 \text { as the highest food } \\
\text { security score) }\end{array}$ & $\begin{array}{l}\text { Score } 0 \\
57.1 \% \\
134.4 \% \\
28.5 \%\end{array}$ & $\begin{array}{l}39.4 \% \\
45.5 \% \\
15.2 \%\end{array}$ & $\begin{array}{l}52.9 \% \\
36.8 \% \\
10.3 \%\end{array}$ \\
\hline \multicolumn{4}{|l|}{$X^{2} 4.287$, df $4, p=.369$} \\
\hline \multicolumn{4}{|l|}{ *Significant at $p<0.05, N=395$} \\
\hline \multicolumn{4}{|c|}{$\begin{array}{l}\text { Next, we used chi-square tests to compare the environmental hygiene, health outcome variables and } \\
\text { bathing behaviour across the groups. We observed that the "at least WASH" had a significantly higher } \\
\text { environmental hygiene than the other groups. } 39.4 \% \text { of the "at least WASH" had higher environmental } \\
\text { hygiene index score than the other groups. Although we observed a slightly high percentage in health } \\
\text { outcomes within the "at least WASH" group compared to other groups, the observed differences in the } \\
\text { health outcomes within the groups were not statistically significant. Details are shown in Table } 3 \text {. }\end{array}$} \\
\hline
\end{tabular}

Table 3

\section{Comparison of health outcomes, environmental hygiene and health habits by groups}




\begin{tabular}{|c|c|c|c|}
\hline & $\begin{array}{l}\text { No intervention } \\
\mathrm{N}(\%)\end{array}$ & $\begin{array}{l}\text { At least WASH } \\
\mathrm{N}(\%)\end{array}$ & $\begin{array}{l}\text { Non-WASH } \\
\text { intervention } \mathbf{N}(\%)\end{array}$ \\
\hline Less environmental issues & $31(10.5)$ & 13(39.3) & $7(10.4)$ \\
\hline \multicolumn{4}{|l|}{$\mathrm{X}^{2} 22.462, \mathrm{df} 2, \mathrm{p}=.000$} \\
\hline $\begin{array}{l}\text { Do not have diarrhoea in the last } \\
\text { month }\end{array}$ & $78(72.4)$ & $7(75.8)$ & $24(63.2)$ \\
\hline \multicolumn{4}{|l|}{$X^{2} 2.618$, df $2, p=.270$} \\
\hline $\begin{array}{l}\text { Frequency of sickness within the last } \\
\text { three months } \\
\text { Frequently sick (at least once every } \\
\text { month) }\end{array}$ & $50(17.1)$ & $6(18.2)$ & $13(19.1)$ \\
\hline \multicolumn{4}{|l|}{$X^{2} 0.172$, df $2, p=.918$} \\
\hline Bathing everyday & $80(37.9)$ & $12(37.5)$ & 18(36.7) \\
\hline
\end{tabular}

\section{$N=395$}

To test our hypotheses, we estimated two structural equation models. The model for the frequency of sickness Model had an excellent fit indices at RMSEA $=0.000, \mathrm{CFI}=1.000$ and $\mathrm{TLI}=1.000$. The standardised beta coefficients for the main effect of bathing on the frequency of sickness and diarrhoea showed that bathing was positively associated to a lower frequency of sickness and diarrhoea (frequency of sickness: $\beta-0.174 p=0.004$; diarrhea: $\beta-0.194 p=0.005$ ). The results also showed that higher environmental hygiene, higher assets, higher food security were positively related to a lower frequency of sickness (environmental hygiene: $\beta 0.168 p=0.016$; assets: $\beta-0.120 p=0.039$; food security: $\beta 0.105 p=$ $0.031)$. The probability of having diarrhoea also reduced with increased environmental hygiene ( $\beta-0.247$ $p=0.002$ ). There was also a significant positive relationship between age, environmental hygiene and bathing. However, we did not find any significant relationship between receiving an "at least WASH intervention" on bathing and the health outcomes measured (No intervention = reference group). Furthermore, the other intervention group (Non-WASH) did not show any significant associations with bathing and health outcomes (No intervention $=$ reference group). Details are in table 4 and 5.

\section{Table 4}

Model result for bathing and frequency of sickness pathway. 


\begin{tabular}{|llll|}
\hline Outcomes & Predictors & Estimate & 2-tailed p-Value \\
\hline Bathing & & \\
\hline & Environment & 0.318 & 0.000 \\
\hline Age & -0.143 & 0.001 \\
\hline Gender & -0.046 & 0.404 \\
\hline Assets & 0.018 & 0.794 \\
\hline Food Security & -0.076 & 0.031 \\
\hline WASH & 0.052 & 0.284 \\
\hline Non-WASH & 0.039 & 0.478 \\
\hline Frequency of sickness & & \\
\hline Environment & 0.168 & 0.016 \\
\hline Age & -0.026 & 0.625 \\
\hline Gender & 0.015 & 0.764 \\
\hline Assets & -0.120 & 0.039 \\
\hline Food Security & 0.105 & 0.031 \\
\hline WASH & -0.032 & 0.542 \\
\hline Non-WASH & 0.064 & 0.210 \\
\hline Bathing & -0.174 & 0.004 \\
\hline a: Female is the reference group; $\mathrm{b}:$ No intervention group is the reference group. & \\
\hline
\end{tabular}

\section{Table 5}

Model result for bathing and diarrhea pathway. 


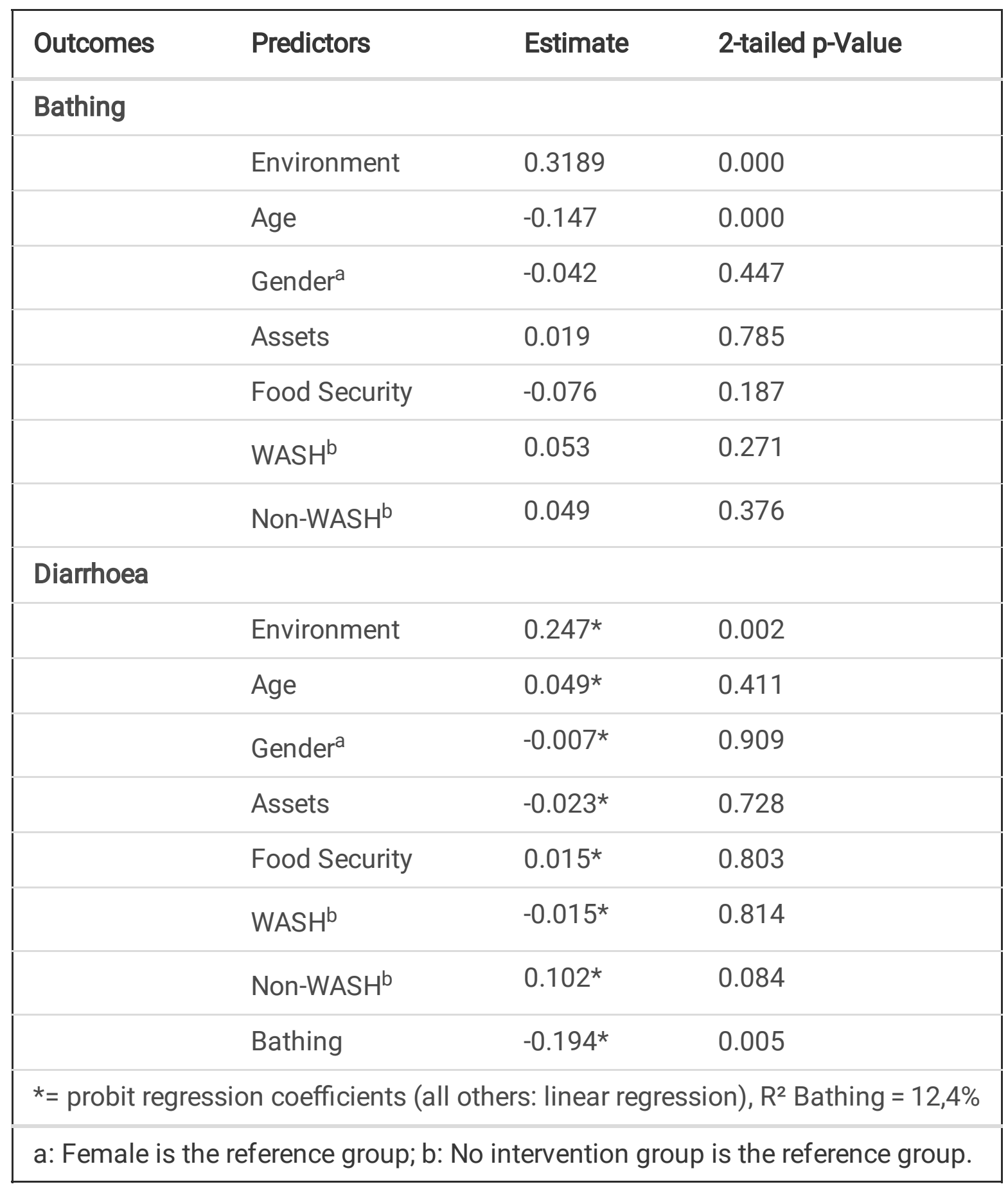

\section{Discussion}

This study investigates the effect of a WASH package intervention on bathing, diarrhoea and sickness and the linkage between bathing and these health outcomes among internally displaced children living in rural non-camp settlement. The key observation of this study is that the quality of environmental hygiene is positively associated with frequency of bathing, the incidence of diarrhoea, and frequency of sickness. The better the environment, the better the health outcomes of the respondent. In addition, bathing also reduced the incidence of sickness and diarrhoea. This study reaffirms the importance of environmental hygiene and personal hygiene behaviour in improving the health outcomes of internally displaced children. Previous studies already established a positive relationship existing between better 
environmental hygiene, personal hygiene and less occurrence of diseases in non-displaced settings(17, 18, 36-38).

Furthermore, our results confirm previous studies that reported that the general state of health is correlated with socioeconomic status and food security. These factors, i.e. poverty and nutrition, have already been established in the literature as determinants of health both in emergency and nonemergency settings (39-41). We find a significant positive relationship for household wealth, food security and frequency of sickness. This implies that higher food security and higher socioeconomic status reduces the frequency of sickness for children.

Although, the limitations (see below) of this study preclude firm conclusions about the contribution of WASH intervention to health outcomes for children. We found some evidence as indicated in the descriptive analysis that the WASH intervention beneficiaries had better environmental conditions despite having a significantly lower household asset score. In addition, our results from the multivariate model indicate that food security and household wealth were positive correlates of health. These factors may likely cause the non-significant health outcomes results we observed across the intervention groups, as the "at least WASH" group were poorer than the other two groups and were likely more or even too vulnerable for us to observe a significant effect of the WASH intervention.

In addition, our results showed that younger children were likely to bath more. It is worth noting that the WASH package intervention in our sampled population was not focused on the infant population. The intervention was received by the adult population. Hence, it might be the case that the children were not adequately sensitised on the importance of personal hygiene. This can be managed by implementing health education programs that are directly focused on school-age children within the schools. Adapting WASH intervention activities to children might help in the sustainability of the WASH intervention through its impact on their health behaviour while also improving their health.

However, our results must be interpreted with caution as this survey has a number of limitations. It is well known that it is extremely difficult to obtain good and statistically rigorous data in an emergency setting $(11,12,42)$. (i) The cross-sectional nature of the data set implies that claims about causality cannot be made. (ii) A lack of security limited the geographic scope, contents of questionnaire and time available for data collection - thus limiting the scope of the topics researched. (ii)The sample size for intervention groups was small and disproportional to the no-intervention group. Larger and proportional intervention groups might have enriched the findings of this study.

\section{Conclusion}

This study is, to the best of our knowledge, the first to explore the relationship between a WASH package intervention and the health behaviour and outcomes for displaced children in Nigeria. The study extends previous literature by providing insight as to the role of environmental hygiene, poverty, food security, and personal hygiene in the health of crisis-affected children. Evidence from this study calls for the need for WASH interventions to focus on the environmental hygiene of households by having all the components 
recommended in the Hygiene Improvement Framework in their implementation of the WASH intervention programs. Procedures and activities that will enhance high-level environmental hygiene within communities and households should be emphasised in WASH intervention. Furthermore, we suggest the need to adapt WASH activities to children so that interventions can maximally impact the health behaviour of this vulnerable sub-population. Children-focused activities should thus be included in the design and implementation of WASH intervention programs within the communities in order to ensure that children are well educated and motivated about the importance of personal and environmental hygiene, consequently resulting in a healthier population. Lastly, additional methodological sound research is urgently needed to further explore these relationships. Such research should be implemented as soon as a relief response is initiated in order to be able to adequately assess the impact of potential interventions. Humanitarian agencies and funders could also integrate research protocols into their humanitarian response in order to provide evidence for the implementation and outcomes of WASH interventions (29).

\section{Abbreviations}

WASH: Water, Sanitation and Hygiene, S.D: Standard Deviation; Hygiene Improvement Framework (HIF)

\section{Declarations}

Ethics approval and consent to participate: Ethical clearance was obtained from the University of Antwerp Ethics Committee for Social Science and Humanities (SHW_17_41_03), and the National Emergency Management Agency (NEMA), Nigeria (NEMA/PRF/179/III).

Consent for publication: Not applicable

Availability of data and materials: The datasets used and/or analysed during the current study are available from the corresponding author on reasonable request.

Competing interests: The authors declare that they have no competing interests

Funding: This research did not receive any funding

Authors' contributions: EA, EW, and DM conceptualised the study design and procedure. EA conducted the data collection. EA and EW analysed the data.EW and DM interpreted the analysis. All authors contributed 
to the writing and editing of the manuscript. All authors read and approved the final manuscript.

Acknowledgements: We acknowledge the assistance and contributions of TEARFUND Nigeria and CRUDAN Adamawa state Staff for the data collection of this study. We also thank the survey participants who shared their experiences as well as the field teams who conducted the interviews for their enthusiasm and dedication.

\section{References}

1. IOM. Nigeria. DTM Round 25 Report. 2018.

2. Rights UNCoH. Report of the Representative of the Secretary-General on In-ternally Displaced Persons: Guiding Principles on Internal Displacement. 199811 February, 1998.

3. Olwedo MA, Mworozi E, Bachou H, Orach CG. Factors associated with malnutrition among children in internally displaced person \'s camps, northern Uganda. Afr Health Sci. 2008;8(4):244-52.

4. Owoaje ET, Uchendu OC, Ajayi TO, Cadmus EO. A review of the health problems of the internally displaced persons in Africa. Nigerian postgraduate medical journal. 2016;23(4):161.

5. Guerrier G, Zounoun M, Delarosa O, Defourny I, Lacharite M, Brown V, et al. Malnutrition and mortality patterns among internally displaced and non-displaced population living in a camp, a village or a town in Eastern Chad. PloS one. 2009;4(11):e8077.

6. Project S. Humanitarian charter and minimum standards in humanitarian response: Practical Action Publishing; 2011.

7. Lam E, McCarthy A, Brennan M. Vaccine-preventable diseases in humanitarian emergencies among refugee and internally-displaced populations. Human vaccines immunotherapeutics. 2015;11(11):2627-36.

8. Connolly MA, Gayer M, Ryan MJ, Salama P, Spiegel P, Heymann DL. Communicable diseases in complex emergencies: impact and challenges. The Lancet. 2004;364(9449):1974-83.

9. Kim G, Torbay R, Lawry L. Basic health, women's health, and mental health among internally displaced persons in Nyala Province, South Darfur, Sudan. Am J Public Health. 2007;97(2):353-61.

10. Terry B, Kanjah F, Sahr F, Kortequee S, Dukulay I, Gbakima A. Sarcoptes scabiei infestation among children in a displacement camp in Sierra Leone. Public Health. 2001;115(3):208-11.

11. Parkinson J. A Review of the Evidence Base for WASH interventions in Emergency Responses. Discussion document. 2009.

12. Yates T, Vujcic JA, Joseph ML, Gallandat K, Lantagne D. Efficacy and effectiveness of water, sanitation, and hygiene interventions in emergencies in low-and middle-income countries: a systematic review. Waterlines. 2018;37(1):31-65. 
13. Ramesh A, Blanchet K, Ensink JH, Roberts B. Evidence on the effectiveness of water, sanitation, and hygiene (WASH) interventions on health outcomes in humanitarian crises: a systematic review. PLoS One. 2015;10(9):e0124688.

14. Gundry S, Wright J, Conroy R. A systematic review of the health outcomes related to household water quality in developing countries. Journal of water health. 2004;2(1):1-13.

15. Hoque BA. Water, sanitation and diarrhoea. Schriftenreihe des Vereins fur Wasser-. Boden-und Lufthygiene. 2000;105:47-52.

16. Yates T, Allen J, Joseph M, Lantagne D. Short-term WASH interventions in emergency response: a systematic review. London: International Initiative for Impact Evaluation (3ie). 2017.

17. Aziz K, Hoque BA, Hasan KZ, Patwary M, Huttly SR, Rahaman MM, et al. Reduction in diarrhoeal diseases in children in rural Bangladesh by environmental and behavioural modifications. Trans $\mathrm{R}$ Soc Trop Med Hyg. 1990;84(3):433-8.

18. McGahey CL. Urban environmental health pilot activities evaluation of progress and lessons learned. EHP Activity Report. 116: EHP; 2001.

19. Torres M, Bendahmane D, Post M, Kleinau E. Combining Hygiene Behavior Change with Water \& Sanitation: A Pilot Project in Hato Mayor, Dominican Republic, April 2000-May 2002. Environmental Health Project Activity Report. 2004;125.

20. Peterson FA, Roberts L, Toole MJ, Peterson DE. The effect of soap distribution on diarrhoea: Nyamithuthu Refugee Camp. Int J Epidemiol. 1998;27(3):520-4.

21. Phillips RM, Vujcic J, Boscoe A, Handzel T, Aninyasi M, Cookson ST, et al. Soap is not enough: handwashing practices and knowledge in refugee camps, Maban County, South Sudan. Conflict health. 2015;9(1):39.

22. Biran A, Schmidt WP, Zeleke L, Emukule H, Khay H, Parker J, et al. Hygiene and sanitation practices amongst residents of three long-term refugee camps in Thailand, Ethiopia and Kenya. Tropical medicine international health. 2012;17(9):1133-41.

23. Darcy J, Stobaugh H, Walker P, Maxwell D. The Use of Evidence in Humanitarian Decision Making ACAPS Operational Learning Paper. Somerville: Feinstein International Centre; 2013.

24. Watson JT, Gayer M, Connolly MA. Epidemics after natural disasters. Emerg Infect Dis. 2007;13(1):1.

25. Samarasekera U, Horton R. Improving evidence for health in humanitarian crises. The Lancet. 2017;390(10109):2223-4.

26. Waldman RJ, Toole MJ. Where is the science in humanitarian health? The Lancet. 2017;390(10109):2224-6.

27. Kayabu B, Clarke M. The use of systematic reviews and other research evidence in disasters and related areas: preliminary report of a needs assessment survey. PLoS currents. 2013;5.

28. Hawkins V, Pérache AH. Humanitarian medicine is more than a technical exercise. The Lancet. 2017;390(10109):2226-8. 
29. Taylor DL, Kahawita TM, Cairncross S, Ensink JH. The impact of water, sanitation and hygiene interventions to control cholera: a systematic review. PLoS one. 2015;10(8):e0135676.

30. Fonseca EF, Penaforte M, Martins M. Hygiene care-bath: meanings and perspectives of nurses. Rev Enferm Ref. 2015;5.

31. Foster JJ. Impact of Multipurpose cash assistance on outcomes for children in Lebanon. 2015.

32. Muthén L, Muthén B. Mplus user's guide. Eight edition. Los Angeles: Muthén \& Muthén; 1998.

33. Bentler PM. Comparative fit indexes in structural models. Psychological bulletin. 1990;107(2):238.

34. Tucker LR, Lewis C. A reliability coefficient for maximum likelihood factor analysis. Psychometrika. 1973;38(1):1-10.

35. Steiger JH, editor Statistically based tests for the number of common factors. the annual meeting of the Psychometric Society lowa City, IA 1980; 1980.

36. Bateman OM, Jahan RA, Brahman S, Zeitlyn S, Laston SL. Prevention of diarrhea through improving hygiene behaviors. The Sanitation and family Education (SAFE) Pilot Project Experience',(42. 1995.

37. Curtis VA. Dirt, disgust and disease: a natural history of hygiene. Journal of Epidemiology Community Health. 2007;61(8):660-4.

38. Zabaneh J, Watt G, O'Donnell C. Living and health conditions of Palestinian refugees in an unofficial camp in the Lebanon: a cross-sectional survey. Journal of Epidemiology Community Health. 2008;62(2):91-7.

39. Budhathoki SS, Bhattachan M, Yadav AK, Upadhyaya P, Pokharel PK. Eco-social and behavioural determinants of diarrhoea in under-five children of Nepal: a framework analysis of the existing literature. Tropical medicine health. 2016;44(1):7.

40. Das JK, Salam RA, Bhutta ZA. Global burden of childhood diarrhea and interventions. Current Opinion in Infectious Diseases. 2014;27(5):451-8.

41. Roberts B, Ocaka KF, Browne J, Oyok T, Sondorp E. Factors associated with the health status of internally displaced persons in northern Uganda. Journal of Epidemiology Community Health. 2009;63(3):227-32.

42. Walden VM, Lamond EA, Field SA. Container contamination as a possible source of a diarrhoea outbreak in Abou Shouk camp, Darfur province, Sudan. Disasters. 2005;29(3):213-21.

\section{Figures}




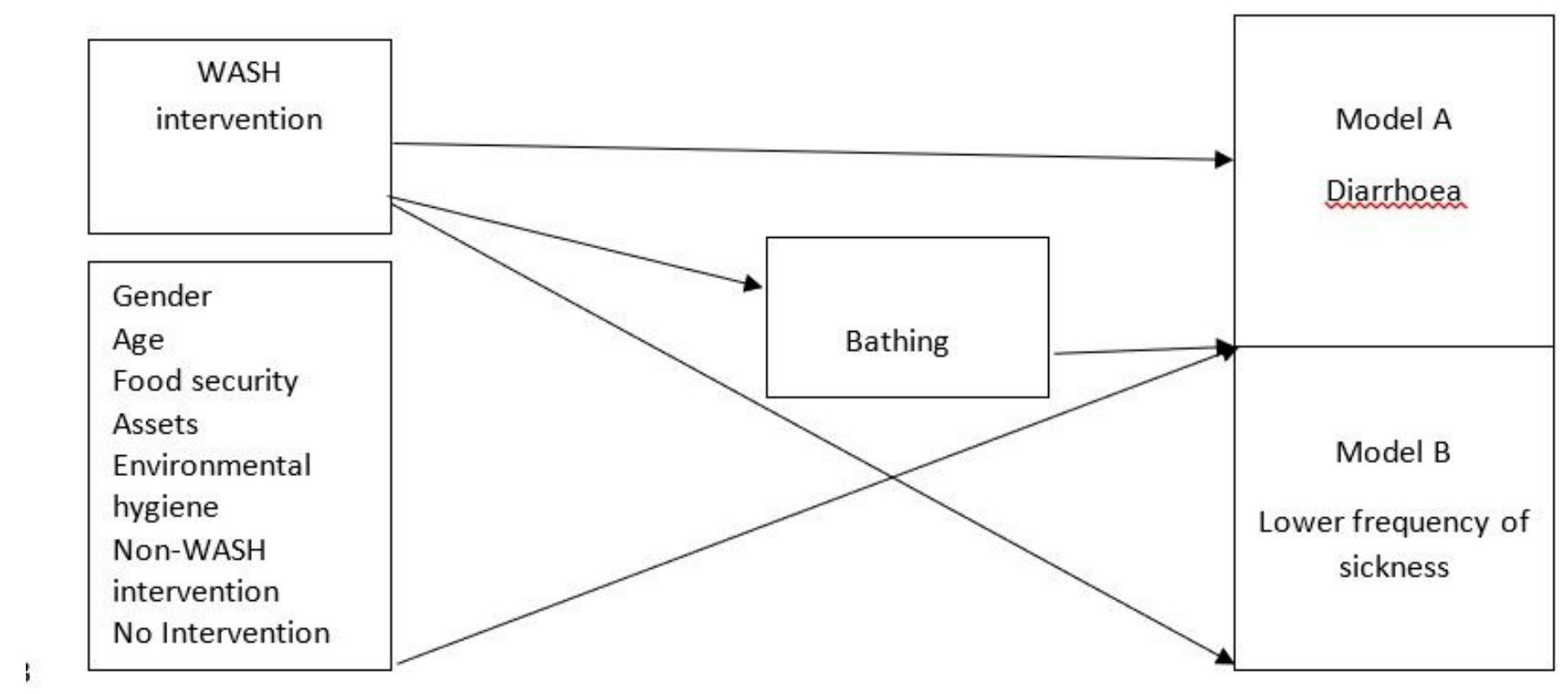

Figure 1

Diagram of models tested 